\title{
Performance of the High-Energy Single- Event Effects Test Facility (SEETF) at Michigan State University's National Superconducting Cyclotron Laboratory (NSCL)
}

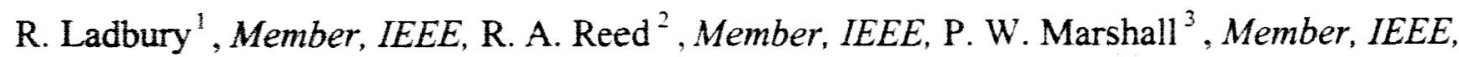 \\ K. A. LaBel ${ }^{2}$, Member, IEEE, R. Anantaraman ${ }^{4}$, R. Fox ${ }^{4}$, D. P. Sanderson ${ }^{4}$, A. Stolz ${ }^{4}$, \\ J. Yurkon ${ }^{4}$, A. F. Zeller ${ }^{4}$, and J. W. Stetson ${ }^{4}$ \\ 1. Orbital Sciences Corporation, Dulles, VA 20166 \\ 2. NASA GSFC, Code 561, Greenbelt, MD 20771 \\ 3. Consultant \\ 4. Michigan State University, East Lansing, MI 48824
}

\begin{abstract}
The performance of Michigan State Univensity's Single-Event Effects Test Facility (SEETF) during its inaugural runs is evaluated. Beam profiles and other diagnostics are presented, and prospects for future development and testing are discussed.
\end{abstract}

\section{INTRODUCTION}

$T^{H}$ HE difficulty of single-event testing for commercial parts in novel packaging technologies (flip-chip, lead-on-chip, and so on) poses a significant barrier to use of these parts in space flight applications. While the unique capabilities conferred by commercial technologies have motivated development of test methods for such parts, these methods are expensive, time-consuming, and in some cases may even alter the radiation response of the part [1], [2]. These difficulties have provided strong motivation for developing test facilities with more penetrating, higher-energy ion beams (see Fig. 1.)

The new single-event effect test facility (SEETF) at Michigan State University's National Superconducting Cyclotron Laboratory (NSCL) delivers highly energetic and penetrating heavy-ion beams (see Table I.) Such ion beams make possible testing of many commercial parts without delidding or other significant modification to the part. In addition, the extended energy range at NSCL makes it possible to reproduce $99 \%$ of the space radiation spectrum in linear energy transfer (LET) and energy for LET > 3 $\mathrm{MeV} \cdot \mathrm{cm}^{2} / \mathrm{mg}$ (see Fig. 2). Moreover, the high ion energy means that testing can be done in air, rather than in vacuum, simplifying issues such as part cooling and access.

This work was supported by the NASA Electronic Parts and Packaging (NEPP) Program, NASA Flight Projects, and the Defense Threat Reduction Agency (DTRA) under IACRO 03-40351.
Here we report on the performance of this facility during its first post-upgrade SEE runs: in February 2004 (with 9574 $\mathrm{MeV} \mathrm{Kr}$ ions) and two runs in May 2004 (with $9574 \mathrm{MeV} \mathrm{Kr}$ and $15048 \mathrm{MeV} \mathrm{Bi}$ ions). (Typical runs involve only a single ion, since switching ions requires a 24-hour tuning time.) We also report results on irradiation of two $256 \mathrm{~K}$ SRAMs (Matra HM65656 and IDT71256). The HM65656 was irradiated previously at other SEE test facilities, so cross sections from SEETF can be compared directly to these results.

\section{SEETF OPERATION}

The NSCL accelerator (see Fig. 3) consists of two coupled cyclotrons (a K500 and a K1200). Attenuation to the desired flux is done upstream of the accelerators to avoid beam detuning at the target. The synchronous operation of the cyclotrons and beam steering optics ensures uniformity of the ion, energy, and charge state. Beam energy degradation, if desired, can be done using either the degrading foils just downstream of the $\mathrm{K} 1200$ or with the degrading foil in the SEETF vault. The first option allows tuning of beam optics downstream of the degraders to ensure uniform beam energy at the target.

As the ions reach the SEETF (see Fig. 4), they pass through a gate valve (which can be opened only when the vault is secured) and into the SEETF beam line.

The SEETF beam line includes two systems for measuring beam uniformity and dosimetry. For fluxes less than $4 \times 10^{2}$ $\mathrm{cm}^{-2} \mathrm{~s}^{-1}$, the parallel plate avalanche counter (PPAC) provides detailed positions in the plane perpendicular to the beam axis (the $\mathrm{X}-\mathrm{Y}$ plane) for individual ion strikes. The second dosimetry system, a four-quadrant thin scintillator (FQS) measurement system, provides detailed dosimetry and rudimentary beam-uniformity information for beam fluxes up 
to $\sim 1.5 \times 10^{5} \mathrm{~cm}^{-2} \mathrm{~s}^{-1}$ over the $5 \mathrm{~cm} \times 5 \mathrm{~cm}$ beam spot. Downstream of the FQS, the ions strike the device under test (DUT). The target positioning stage provides translation in the X-Y plane and rotation about the vertical axis (in $\theta$ ). Fig. 5 shows the experimental area in the SEETF vault. Fig. 6 shows a picture of the user control room.

\section{FACILITY CONTROL}

The SEETF is controlled from the user control room (Fig. 6) or the SEETF experimental vault (Fig. 5) by two computer systems. A Windows-based system controls target positioning, the downstream degrader, and other aspects pertaining to the SEETF beam line elements. The Windows system also starts and stops irradiation of the part.

Data acquisition is handled by a Linux-based system, which controls the beam-monitoring equipment and display, storage of facility data for the run, and so on. It also allows the user to save the data at the end of the run.

Control of the beam (including flux, quality, and tuning) is exercised by the accelerator operators. Users may request changes by calling the operator in the control room. Flux can usually be incremented or decremented in a few minutes. Tuning for beam uniformity may be more involved but is usually completed within 15 to 30 minutes. Beam energy degradation to increase ion LET can involve a retune to ensure uniform energy.

\section{BEAM Quality AND DOSIMETRY}

During the February and May 2004 beam runs, both the PPAC and the FQS were used to monitor the beam quality and measure dosimetry. Because the PPAC provides more detailed information on uniformity over the $5 \mathrm{~cm} \times 5 \mathrm{~cm}$ beam spot size, initial runs were conducted at low flux with the PPAC in the beam line. In subsequent runs, the flux was raised by decreasing the attenuation upstream of the K 500 cyclotron, and the PPAC was removed. This produces a beam profile with uniformity comparable to the low-flux, highattenuation beam. The FQS provides information sufficient to indicate any major changes in uniformity. The procedure of beginning with low flux in order to use the PPAC and then transitioning to the FQS was followed whenever the beam was retuned.

Fig. 7 illustrates the beam quality characteristic of the February and May 2004 runs. The upper left plot shows the PPAC readout (in the lab, fluence is color-coded as red $=$ high, blue = low). The upper right and lower left plots show, respectively, histograms of counts in the PPAC within a central slice along the $\mathrm{Y}$ or $\mathrm{X}$ axis. The lower right plot shows counts in each quadrant of the FQS.

Beam quality remained uniform ( $>85 \%$ uniformity) over the $5 \mathrm{~cm} \times 5 \mathrm{~cm}$ beam spot. Fluxes ranged from $10^{2}$ to $10^{5}$ $\mathrm{cm}^{-2} \mathrm{~s}^{-1}$, and could be changed using the upstream attenuator in less than 30 minutes ( $<5$ minutes was typical). During the February 2004 run, the upstream degraders were used to change the energy of the $\mathrm{Kr}$ ion beam, bumping the
LET from $6.3 \mathrm{MeV} \cdot \mathrm{cm}^{2} / \mathrm{mg}$ to $8.7 \mathrm{MeV} \cdot \mathrm{cm}^{2} / \mathrm{mg}$. The beam optics required less than 2 hours for retuning after the change.

\section{CROSS-FACILTY COMPARISON}

To assess SEETF data quality in relation to that from other facilities, we irradiated a Matra HM65656 256 K SRAM, dubbed DUT \#30, which had been irradiated previously at the Brookhaven SEUTF and TAASC. Fig. 8 indicates the excellent agreement between facilities.

\section{ION LET DETERMINATION}

Determining ion LET after the beam has traversed DUT overlayers can be challenging. Monte Carlo transport codes like SRIM [4] or empirical fits to data such as LISE [5] can be effective for overlayers of known thickness and composition. However, assumptions about overlayer compositions are risky, especially for plastic-encapsulated parts. Table II shows results for several packaged and delidded Matra 65656 and IDT71256 SRAMs for the degraded and undegraded $\mathrm{Kr}$ beams. The 2 orders of magnitude drop in cross section exhibited by the plastic packaged IDT71256 versus the delidded version for the degraded $\mathrm{Kr}$ beam indicates that the ions are "ranging out" in the package before they reach the sensitive volume in the silicon. This indicates that the plastic packaging was significantly denser than would be predicted for a typical pure polymer. This is not surprising, since many plastics have high glass content for thermal, structural, or other reasons.

An alternative to estimating LET is to measure it using charge collection spectroscopy [6]. This technique uses a delidded (but not necessarily functional) part identical to the DUT and an ion beam of known LET incident on the bare die to measure the scaling relation between charge collected and LET (see Fig. 9.) The charge collected for the same peak for a packaged device then determines the LET of the ions after they have traversed the device overlayers (see Fig. 10).

\section{COMPLEMENT TO OTHER FACILITIES}

The SEETF at NSCL offers highly penetrating energetic ion beams in combination with the dosimetry, targeting, and other facilities needed to produce high-quality SEE data. However, the facility cannot supplant existing heavy-ion SEE laboratories. The cost of beam time $(\$ 2,300$ /hour to $\$ 2,700$ /hour) is significantly higher than that at lower energy facilities such as the Brookhaven SEUTF, Berkeley, and Texas A\&M (although if the metric is cost per MeV per amu or cost per micron of range, the SEETF is a bargain). The time available for SEE studies is limited ( $<600$ hours per year). Perhaps the most significant limitation of the facility is that unless the user is willing to pay a significant premium for beam tuning, SEE runs will generally have to be conducted with a single ion and therefore over a limited LET range.

The capabilities of the SEETF complement those of other heavy-ion facilities. The longer ranges of NSCL's ions will be invaluable for some testing requirements, e.g., when several devices need to be screened for single-event latchup and other 
serious error modes, with the best performers being subjected to more thorough testing. Other studies where high-energy ions would be invaluable include investigation of track structure effects and of energy dependence of susceptibility to some SEE mechanisms (e.g., single-event gate rupture [7]).

\section{FUTURE DEVELOPMENT}

Because the SEETF is a new facility, it is still subject to improvement. The highest priorities for near-term development are intended to increase the range of LETs and penetration depths available. One upgrade involves installing a translation stage to move the target along the beam axis, reducing the air gap and thereby slightly increasing the energy and range of the ions incident on the DUT. Such capability could be important for thick devices when ion penetration is marginal. This capability, however, also requires refinement of the targeting system. During the May 2004 run, an extension was mounted on the target assembly to place the part as close to the beam exit port as possible. The DUT was then positioned by hand at the center of the beam aperture.

Another project involves adding rotational capability to the downstream degrader foil, giving a nearly continuous range of effective degrader thicknesses (and LETs). In conjunction with this capability, an ion energy measurement system for degraded beams will allow the user to measure the energy spectrum of degraded beams and estimate systematic errors introduced by beam straggling.

\section{CONCLUSION}

With the completion of the inaugural run of the SEETF at Michigan State University, the radiation community has a powerful new tool, both for penetrating novel package technologies and for the simulation of high-energy ions in the space environment. The results of these runs indicate both the strengths of this new facility-its high energy, penetrating power, and ease of use-as well as its weaknesses-the difficulty in switching ions to map out a full cross section versus LET curve. These characteristics suggest that the MSU facility represents an excellent complement to other existing test facilities. Questions about the SEETF should be directed to Ray Ladbury at NASA Goddard Space Flight Center.

\section{ACKNOWLEDGMENT}

The authors would like to acknowledge the sponsors of this effort: The NASA Electronic Parts and Packaging (NEPP) Program, NASA Flight Projects, and the Defense Threat Reduction Agency (DTRA) under IACRO 03-40351.

\section{REFERENCES}

[1] R. Harbo-Sorensen, et al,, Heavy-ion single-event effects testing of lead-on-chip assembled high-density memories, IEEE Trans. Nucl. Sci., vol. 50, no. 6, p. 2322, 2003

[2] G. M. Swift, Single-event testing using heavy-ion irradiation through thick layers of material, Proceedings of the 6th European Conference on Radiation and Its Effects on Components and Systems, CD-ROM, 2001
[3] N. Anantaraman, NSCL Single Event Effects Test Facility users manual (for most recent version, contact $R$. Anantaraman, National Superconducting Cyclotron Laboratory, Michigan State University, East Lansing, M1 48824-1321).

[4] J. F. Ziegler, et al.. The Stopping and Range of Ions in Solids, New York: Pergamon, 1984.

[5] Available at http://groups.nscl.msu.edu/lise/lise.html.

[6] R. A. Reed, et al., In-situ measurement of the particle linear energy transfer using the sensitive junctions of the device under test, Proceedings of the 6th European Conference on Radiation and Its Effects on Components and Systems, CD-ROM, 2001.

[7] J. Titus, et al., SEE characterization of vertical DMOSFETs: An updated test protocol, IEEE Trans. Nucl. Sci., vol. 50, no. 6, p. 2341, 2003

TABLE I

AVAILABLE IONS, RANGES, AND LETS

\begin{tabular}{|l|c|c|c|c|c|}
\hline Ion & Facility & $\begin{array}{c}\text { Max. } \\
\text { Energy } \\
(\mathrm{MeV} / \mathrm{amu})\end{array}$ & $\begin{array}{c}\text { LET in Si } \\
\left({\left.\mathrm{MeV} \cdot \mathrm{cm}^{2} / \mathrm{mg}\right)}\right.\end{array}$ & $\begin{array}{c}\text { Range in Si } \\
(\mu \mathrm{m})\end{array}$ & $\begin{array}{c}\text { Bragg-Peak } \\
\text { LET in Si }\end{array}$ \\
\hline $\mathrm{Ar}-36$ & $\mathrm{NSCL}$ & 143 & 1.50 & 8860 & 18 \\
\hline $\mathrm{Kr}-78$ & $\mathrm{NSCL}$ & 121 & 6.08 & 4440 & 40 \\
\hline $\mathrm{Xe}-136$ & $\mathrm{NSCL}$ & 131 & 14.1 & 3070 & 69 \\
\hline $\mathrm{Bi}-209$ & $\mathrm{NSCL}$ & 72 & 42 & 1100 & 100 \\
\hline
\end{tabular}

TABLE II

SEU CROSS SECTIONS FOR PRIMARY AND DEGRADED BEAMS

\begin{tabular}{|c|c|c|c|c|}
\hline Part & Packaging & $\begin{array}{l}\text { Incident } \\
\text { Energy } \\
\text { (MeV) }\end{array}$ & $\begin{array}{l}\text { LET } @ \text { die } \\
\text { surface } \\
\left(\mathrm{MeV} \cdot \mathrm{cm}^{2} / \mathrm{mg}\right)\end{array}$ & $\begin{array}{l}\text { Average Cross } \\
\text { Section }\left(\mathrm{cm}^{2}\right)\end{array}$ \\
\hline IDT71256 & $\begin{array}{l}\text { Lidded } \\
\text { Plastic }\end{array}$ & 9574 & $N / A$ & $2.01 \times 10^{-3}$ \\
\hline IDT71256 & Delidded & 9574 & 6.3 & $1.08 \times 10^{-3}$ \\
\hline IDT71256 & $\begin{array}{l}\text { Lidded } \\
\text { Plastic }\end{array}$ & 5953 & $\mathrm{~N} / \mathrm{A}$ & aseato' \\
\hline IDT71256 & Dolidded & 5958 & 8.7 & $5.15 \times 10^{-3}$ \\
\hline M65656 & $\begin{array}{l}\text { Lidded } \\
\text { Plastic }\end{array}$ & 9574 & 6.3 & $4.89 \times 10^{-2}$ \\
\hline M65656 & Delidded & 9574 & 7.1 & $1.35 \times 10^{-1}$ \\
\hline A465656 & $\begin{array}{l}\text { Lidded } \\
\text { Hermetic }\end{array}$ & 5953 & 11.7 & $1.61 \times 10^{-2}$ \\
\hline$M 65656$ & Delidded & 5953 & 6.3 & $1.25 \times 10^{-2}$ \\
\hline
\end{tabular}

a)

b)
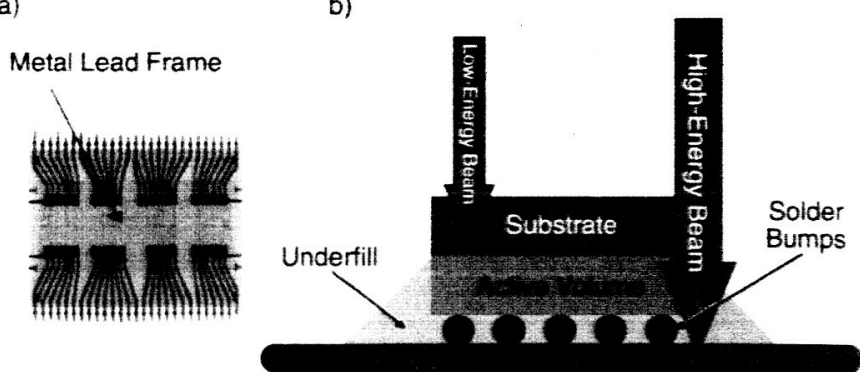

Fig. 1. High-energy ion beams can penetrate the thick overburdens associated with commercial microchips, e.g., metal lead frames (a) or flipchip packages (b). 


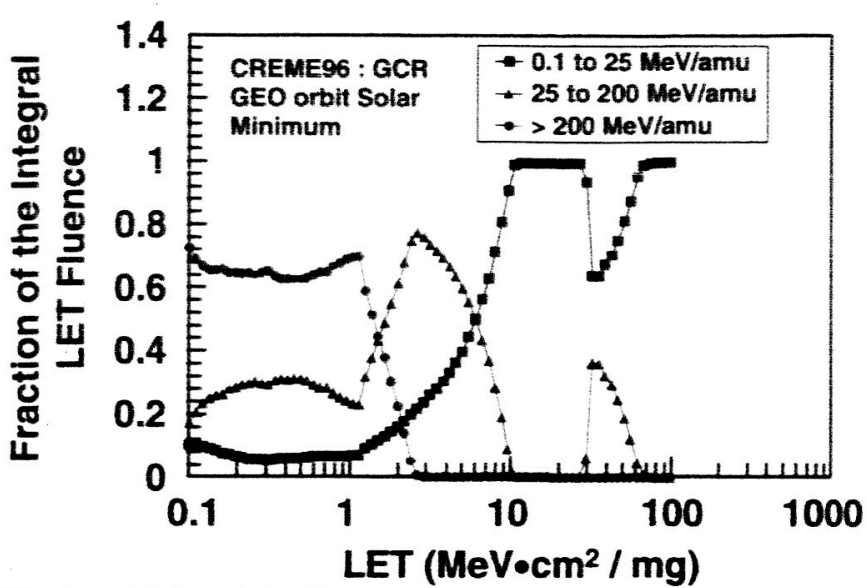

Fig. 2. Addition of the high-energy ions (with $60-143 \mathrm{MeV} /$ nucleon) at NSCL allows simulation of $\sim 99 \%$ of the space radiation LET-energy phase space for $L E T>3 \mathrm{MeV} \cdot \mathrm{cm}^{2} / \mathrm{mg}$.

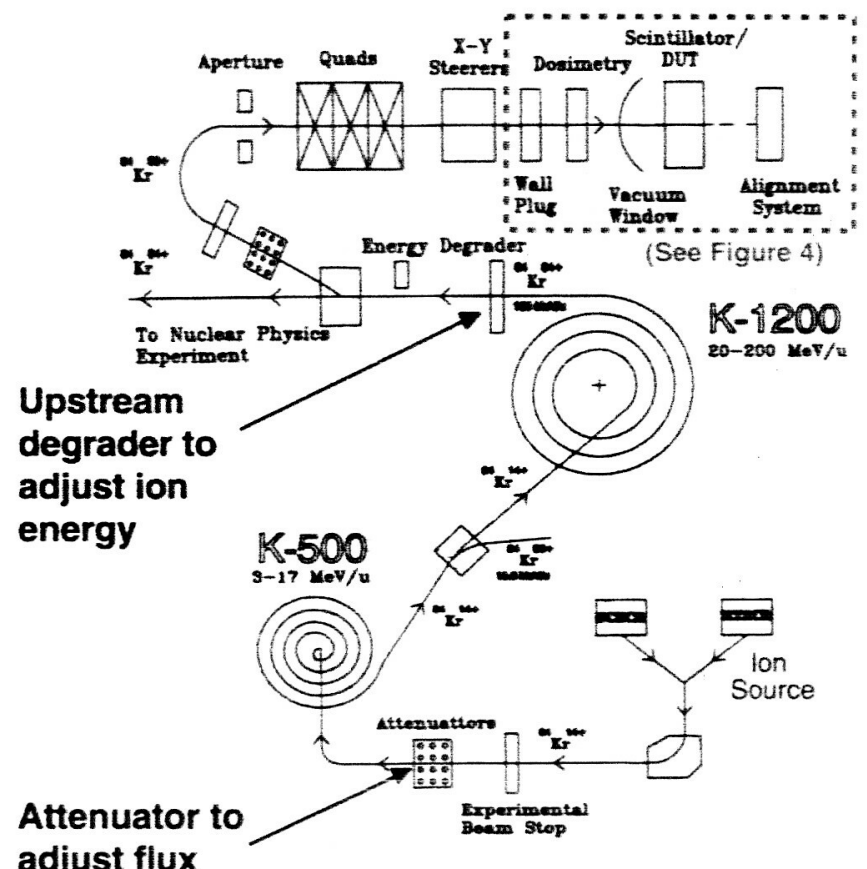

Fig. 3. Schematic of the main features of the accelerator and beam optics (below) and the SEETF beam line (red box). Fig. 4 shows an expanded version of the main elements within the SEETF experimental area (inside red rectangle.)

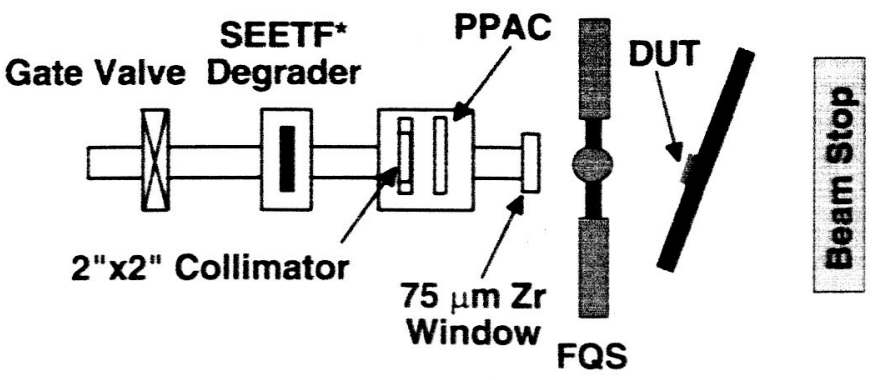

Fig. 4. The main elements inside the SEETF experimental vault.

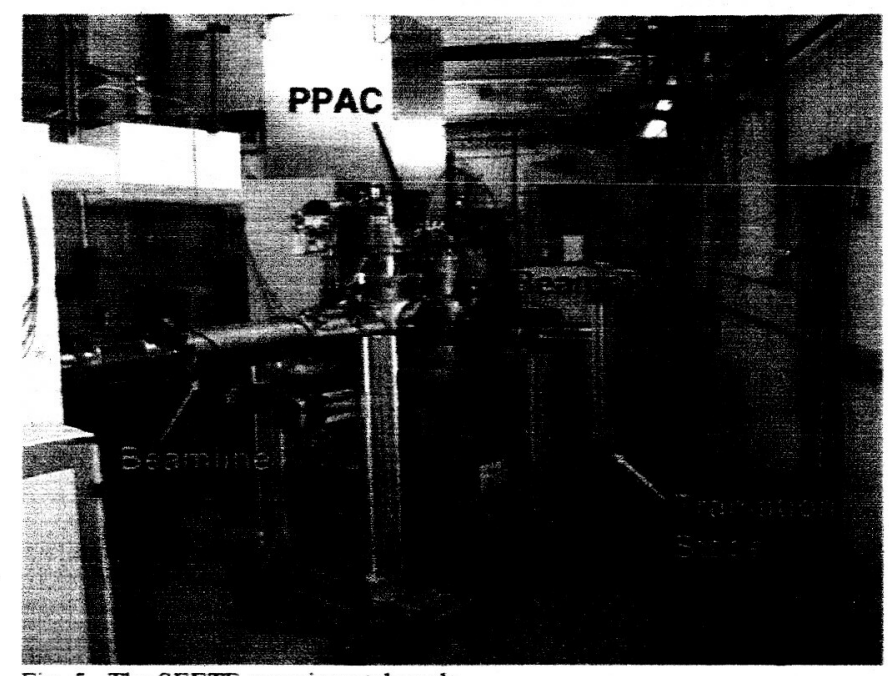

Fig. 5. The SEETF experimental vault.

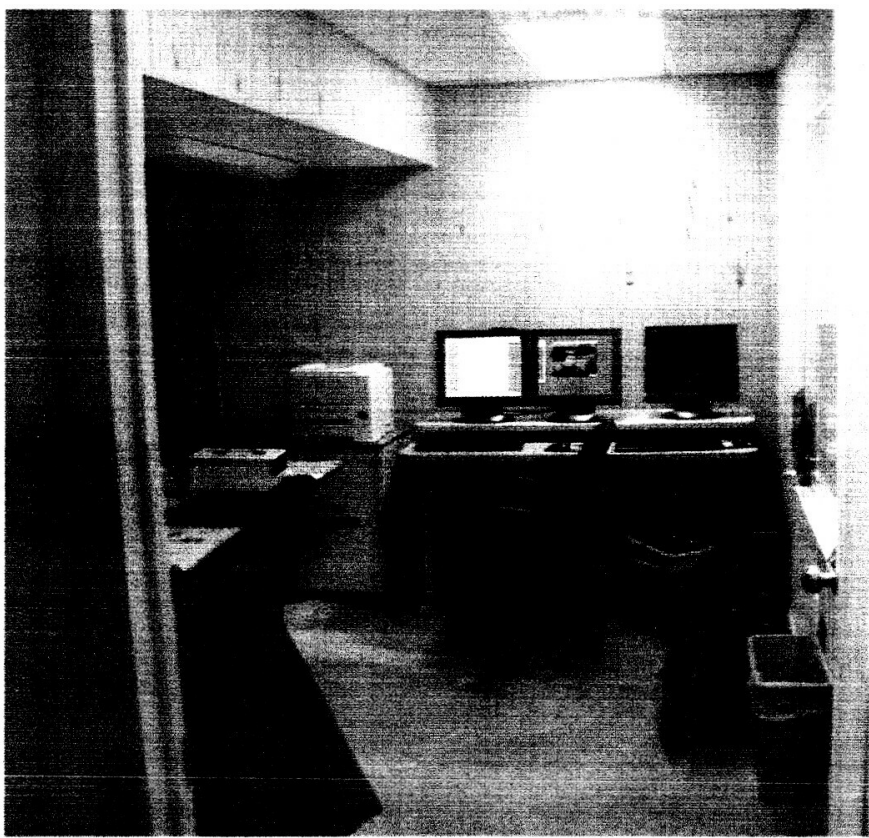

Fig. 6. Picture of the user room. 


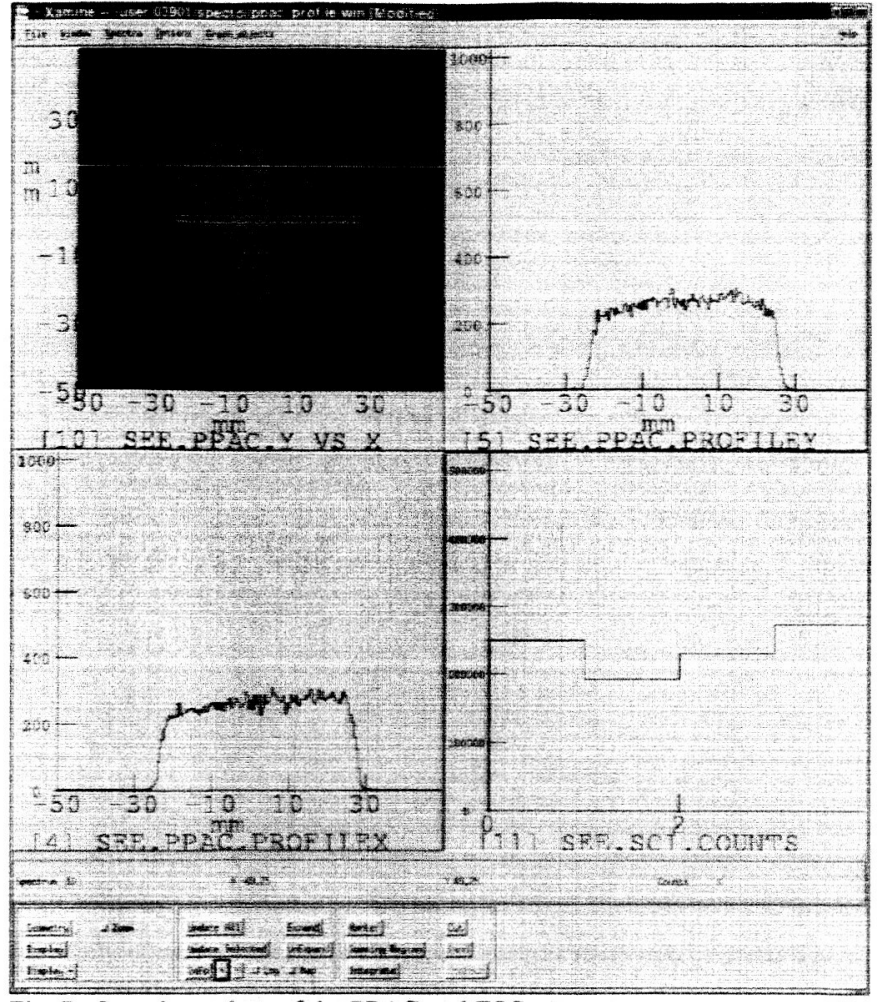

Fig. 7. Sample readout of the PPAC and FQS.

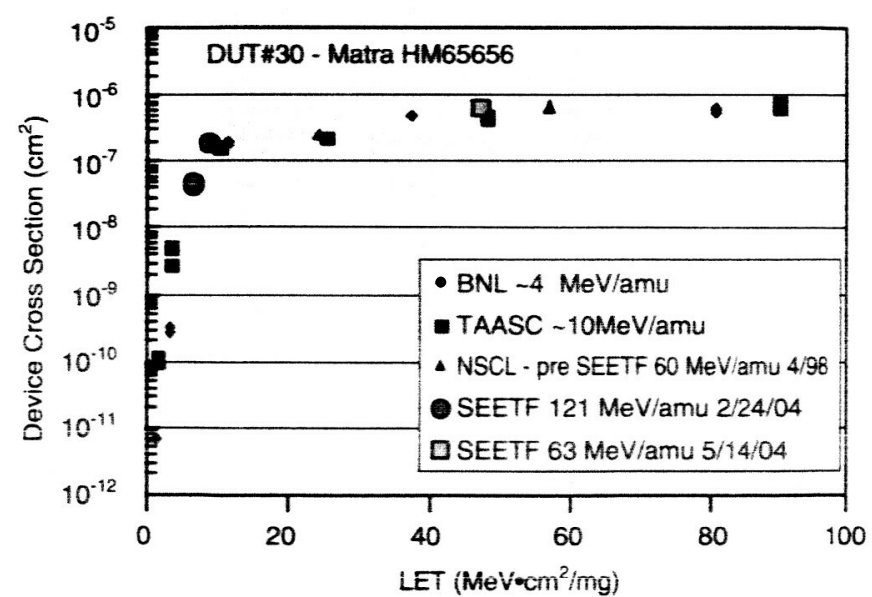

Fig. 8. The same Matra HM65656 irradiated at TAASC, NSCL, Michigan State University (pre-upgrade) and Brookhaven yields consistent cross section vs. LET curves over beam energies spanning a factor of 40 .

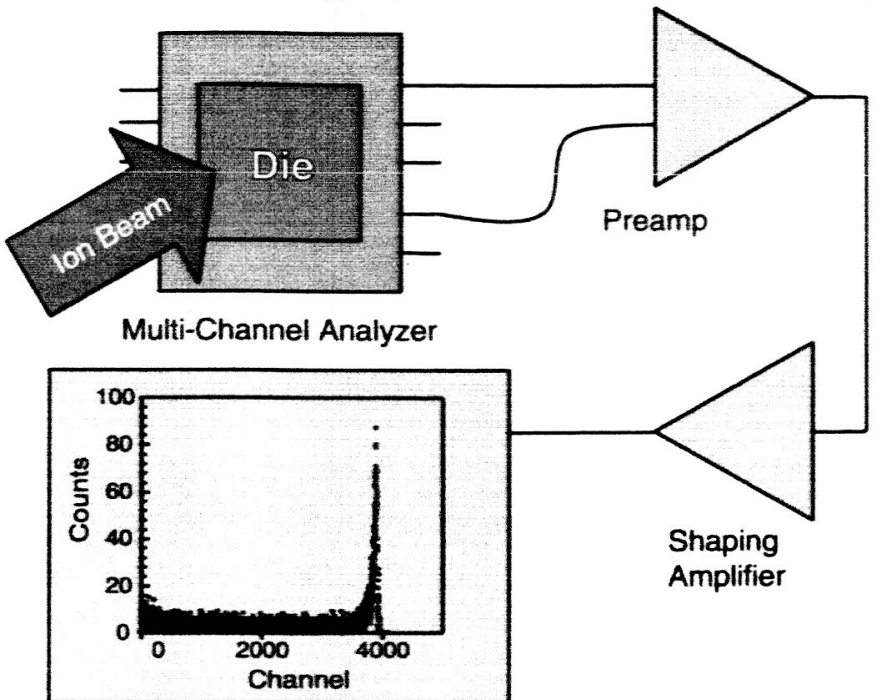

Fig. 9. Charge collection spectroscopy setup.

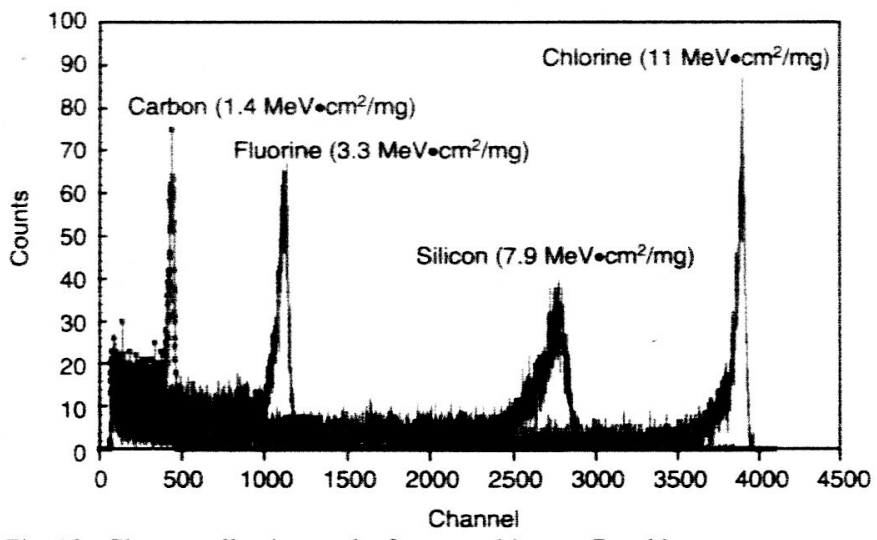

Fig. 10. Charge-collection peaks for several ions at Brookhaven.

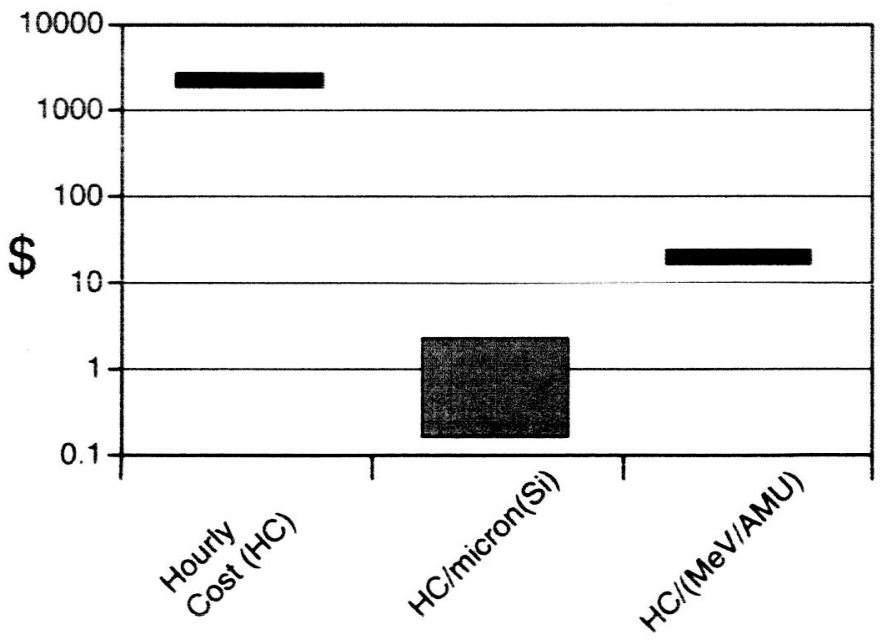

Fig. 10. Selecting appropriate cost metrics for SEETF. 